\title{
Wind Farm Power Curves and Power Distributions
}

\author{
Andrés E. Feijóo-Lorenzo
}

check for updates

Citation: Feijóo-Lorenzo, A.E. Wind Farm Power Curves and Power Distributions. Energies 2022, 15, 182. https://doi.org/10.3390/en15010182

Received: 8 December 2021 Accepted: 24 December 2021 Published: 28 December 2021

Publisher's Note: MDPI stays neutral with regard to jurisdictional claims in published maps and institutional affiliations.

Copyright: (C) 2021 by the author. Licensee MDPI, Basel, Switzerland. This article is an open access article distributed under the terms and conditions of the Creative Commons Attribution (CC BY) license (https:/ / creativecommons.org/licenses/by/ $4.0 /)$.
Departamento de Enxeñería Eléctrica, EEI, Campus de Lagoas-Marcosende, Universidade de Vigo, 36310 Vigo, Spain; afeijoo@uvigo.gal; Tel.: +34-986-812055

There seems to be an agreement in the scientific community. The use of conventional energy sources is causing a negative impact on the atmosphere. This is mainly due to the emission of greenhouse gases, released as by-products of the generation processes. The effect is global warming. The shift towards renewables should contribute to mitigate it. Among them, wind energy has emerged as a very important one. It has experienced a strong growth in recent years and its share in some electric power networks is actually significant.

All of an industry and its associated research have been developed regarding wind energy. Different manufacturers proliferated in a competence that resulted in a wide variety of generating converters called wind turbines. A determining feature of a wind turbine is its power curve. It establishes a relation between the wind speed at its hub height and the power that can be extracted by the machine and, therefore, injected into the electrical power network. A wind turbine power curve is obtained under standard conditions, although wind turbines hardly ever operate under such conditions.

Wind turbines are generally grouped, constituting the electrical power stations called wind farms. The power curve of a wind farm is not exactly obtained as the sum of the power curves of its different wind turbines. Such a calculation would be a rough approximation. In a wind farm, the relation between wind speed and generated power depends on its layout. In addition to electrical losses due to its cabling system, aerodynamic losses due to wakes should not be neglected when estimating the total production.

Wakes are produced when wind passes through the rotor of a wind turbine and loses part of its energy, captured by the machine. When there are one or more wind turbines in the direction of the wind speed, wakes are formed and cause such losses in the total generated power. Therefore, the direction of the wind is also important in the analysis. For a given wind turbine located in a wind farm with its particular layout, there is a number of wind turbines in the trajectory of the wind, depending on its direction.

This Special Issue aimed to attract contributions on the calculation of the power generated by wind farms, and on their power distributions. Four papers were accepted. Some comments about them can be found in the next paragraphs.

The authors of [1] worked on an algorithm that allowed them to calculate the optimized hub height of wind turbines, with the goal of minimizing the cost of energy. This hub height was determined by the calculation of the annual energy production and by incorporating the cost increase due to the hub height. Although, in their case, they used the algorithm together with the data of a Korean database and applied it in a regional case, they expect it to serve as a good guideline for using it in different regions.

The offshore wind characteristics and wind energy potential of the Bohai Bay, in China, were statistically analyzed in [2]. With this aim, the authors used two-year offshore wind data taken in time intervals of 1 second. The resource assessment was performed with the help of Nakagami and Rician distributions, which, according to the authors' comments, operated very reasonably when estimating wind speed distributions and the wind potential, except for one month, August, due to the lack of data. The authors state that the use of Weibull and Rayleigh's distributions was also satisfactory in those simulations, but the best fits were achieved with the help of Nakagami's distribution.

In [3], a computational method was presented, for the simulation of wind speeds and for the calculation of the distributions of wind farm power curves. In accordance with 
some previous comments of this editorial, wake effects were taken into account in this work and, also, orography effects. Logistic functions were used for the simulation of wind turbine power curves, and wind farm power curves based on the logistic function were derived, by considering the mentioned wake effects. The orography was included in the calculations by means of the slope. Four different slopes were considered for obtaining different wind farm power curves, depending on them. The main novelty of this paper is that it presents a much better approach to the study of the influence of wakes in a complex terrain. In fact, the work was inspired by a previous work by one of the authors, where only plain terrains were assumed.

Finally, Ref. [4] presents a review of state-of-the-art reviews on wind energy-related subjects, which includes a section devoted to the analysis of state-of-the-art studies regarding wind turbine power curves.

In all knowledge fields, further research and developments are always needed and welcome, and this Special Issue is not an exception. For instance:

- Along the years, interesting discussions have arisen regarding different wake models, and important developments have been publish in this regard.

- The previous comment is also valid for wind turbine and wind farm power curves, where several proposals can be found in the literature, including the use of logistic functions for the representation.

- $\quad$ The Weibull and Rayleigh distributions have been traditionally accepted as very good approximations for the statistical representation of average wind speeds, although studies with a variety of proposals have also been published and, nowadays, it is not clear that those distributions are always the best choices.

- $\quad$ Layout wind farm optimization has also attracted many researchers and very interesting developments based on different optimization algorithms can also be found in the related literature.

- The previous point is also important because, in the future, not only will new wind farms be projected, but also the repowering of old installations will be proposed.

All these fields are closely related to the topic of this Special Issue and, therefore, future developments will be proposed for certain.

Funding: This research received no external funding.

Conflicts of Interest: The author declares no conflict of interest.

\section{References}

1. Lee, J.T.; Kim, H.G.; Kang, Y.H.; Kim, J.Y. Determining the Optimized Hub Height of Wind Turbine Using the Wind Resource Map of South Korea. Energies 2019, 12, 2949. [CrossRef]

2. Yu, J.; Fu, Y.; Yu, Y.; Wu, S.; Wu, Y.; You, M.; Guo, S.; Li, M. Assessment of Offshore Wind Characteristics and Wind Energy Potential in Bohai Bay, China. Energies 2019, 12, 2879. [CrossRef]

3. Tao, S.; Xu, Q.; Feijóo, A.; Kuenzel, S.; Bokde, N. Integrated Wind Farm Power Curve and Power Curve Distribution Function Considering the Wake Effect and Terrain Gradient. Energies 2019, 12, 2482. [CrossRef]

4. Sawant, M.; Thakare, S.; Rao, A.P.; Feijóo-Lorenzo, A.E.; Bokde, N.D. A Review on State-of-the-Art Reviews in Wind-Turbineand Wind-Farm-Related Topics. Energies 2021, 14, 41. [CrossRef] 